\title{
Visualizing Demographic Representation in ASA Sections: The Case of Race/Ethnicity and Gender in CITAMS
}

\author{
Daniel Karell \\ Yale University, New Haven, CT, USA \\ Andrew M. Lindner* \\ Skidmore College, Saratoga Springs, NY, USA
}

July 30, 2021

* Corresponding author: Andrew Lindner (alindner@skidmore.edu), Skidmore College, 815 N. Broadway, Saratoga Springs, NY 12866

Acknowledgements: The authors would like to the other members of the CITAMS DEI Committee, Christine Tomlinson, Isha Bhallamudi, and Michael Miner for their contributions to designing the survey as well as the CITAMS members who participated in the survey. We would also like to thank the American Sociological Association's Director of Research, Professional Development, and Academic Affairs Dr. Erynn Masi de Casanova for providing aggregate figures on the gender and racial identities of CITAMS Council Members and award winners. Daniel Karell and Andrew Lindner contributed equally to this visualization report. 


\begin{abstract}
The American Sociological Association (ASA) and its sections have taken on new efforts at increasing diversity, equity, and inclusion (DEI) in recent years. In 2020-21, the Communication, Information Technologies, and Media Sociology (CITAMS) section's DEI Committee conducted a survey of section elected officials and award winners $(n=42)$. This visualization reports the results of survey participants' self-identified demographic group memberships across section offices and awards, and compares them to section- and ASA-wide baselines. By doing so, the visualization offers an example of how sections can assess the racial and gender representation of their section leadership and award recipients relative to demographics of the section and ASA as a whole.
\end{abstract}

Keywords: diversity, inclusion, representation, organizations, American Sociological Association 


\section{Explanation of data visualization}

Race and gender inequities are structural features of the formation and functioning of organizations (Ray 2019; Williams, Muller, and Kilanski 2012; Avent-Holt and Tomaskovic-Devey 2019).

However, organizations that introduce initiatives to increase diversity tend to achieve that goal, especially when combined with structures of accountability (Dobbin, Schrage, and Kalev 2015). Doing so can have profound consequences for organizations: elevating the representation of women and BIPOC people in positions of organizational leadership reshapes both the distribution of power within the organization (Ray 2019) and the choices of people throughout in the organization (Mullen and Baker 2018).

In light of the importance and impact of race and gender inequity in organizations, the American Sociological Association (ASA) has taken numerous steps to build a more diverse, equitable, and inclusive organization. ${ }^{1}$ As part of this effort, the Communication, Information Technologies, and Media Sociology (CITAMS) ASA section-joining a number of other sections-formed its own DEI committee in 2020. The committee recognized that while there are many aspects to working towards a more welcoming and inclusive organization, an important first step is assessing how the section's membership is (or is not) represented in elected leadership positions and among award winners. To so do, we conducted a survey to gauge how section members who have achieved section-wide recognition demographically reflect CITAMS membership and ASA membership as a whole.

ASA provides annual aggregate data on the gender and race/ethnicity of section membership. ${ }^{2}$ Working with ASA's Director of Research, we received aggregate figures on the racial and gender identities of Council Members and award winners over the past five years. However, more granular data on individual offices (e.g., Chair, Secretary/Treasurer) were unavailable. Moreover, because some individuals had held multiple positions in the section within a five-year window, ASA's data, which are based on individuals rather than the positions, effectively under-counted multiple position-holders.

Conducting an original survey of section leaders and award winners allowed the CITAMS DEI Committee to gather data on a wider range of identities, disentangle individuals from positions, and examine the demographic patterns of particular positions. We developed a survey (see Supplemental Information), which was distributed in March 2021 to the population of CITAMS elected officials and award winners over the past five years. During that period, 74 unique individuals held 108 elected positions and/or were award winners. After an initial solicitation and two reminder emails, we received 42 responses (57\% response rate).

The visualization presented in Figure 1 compares the gender and racial/ethnic demographics of survey respondents in six positions (Best Paper winners, Best Student Paper winners, Council Members, Nominations Committee Members, Secretary/Treasurers, and Section Chairs) to those of the CITAMS section membership and ASA membership (using the 2019 proportions available from ASA). The solid bars indicate the proportions of the survey respondents (i.e., elected officials and

\footnotetext{
${ }^{1}$ https://www.asanet.org/diversity-equity-inclusion

${ }^{2}$ https://www.asanet.org/academic-professional-resources/data-about-discipline/asamembership\#sections
} 
award winners). The solid and dashed lines represent the proportion of ASA and CITAMS members reporting a given demographic category, respectively. Both these ASA and CITAMS proportions use ASA's demographic labels (e.g., the percentage of "Hispanic/Latino(a)" ASA members).

As Figure 1A shows, male members are overrepresented compared to both the section and ASA in all positions except Secretary/Treasurer and Chair. Similarly, white members are overrepresented in every position except for Best Student Paper (Figure 1B). In several positions, Asian/AsianAmerican members are represented at or above ASA and CITAMS proportions. By contrast, several positions, including Council Members and Best Paper Winners have no Black/African-American representation at all. Because these figures draw on a sample of a small population, there are some positions where the results can be misleading. For example, it is not the case that CITAMS has had only white Chairs in the past five years, as suggested by Figure 1A. However, such a result is only possible when white people are the vast majority of all section Chairs.

As a medium-sized section ( $33^{\text {rd }}$ out of 53 sections in membership) and with gender and racial demographics that are largely comparable to ASA's overall proportions, CITAMS offers a useful case for demonstrating how ASA sections may assess their own demographic representation. Our visualization is an example of how all ASA sections can begin to consider and share the various forms of demographic representation in the people they officially recognize through elected positions and awards. 


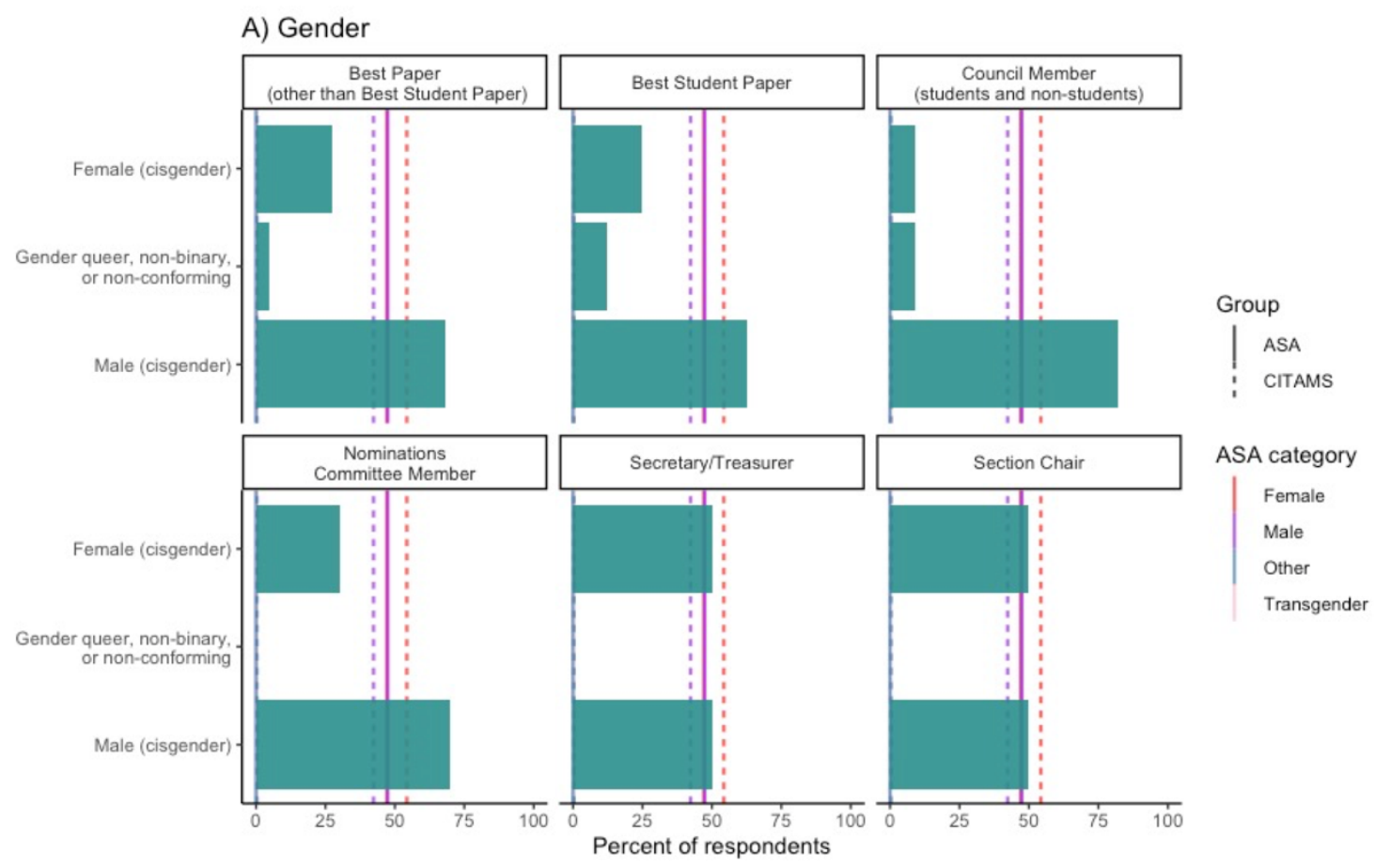

\section{B) Race and ethnicity}
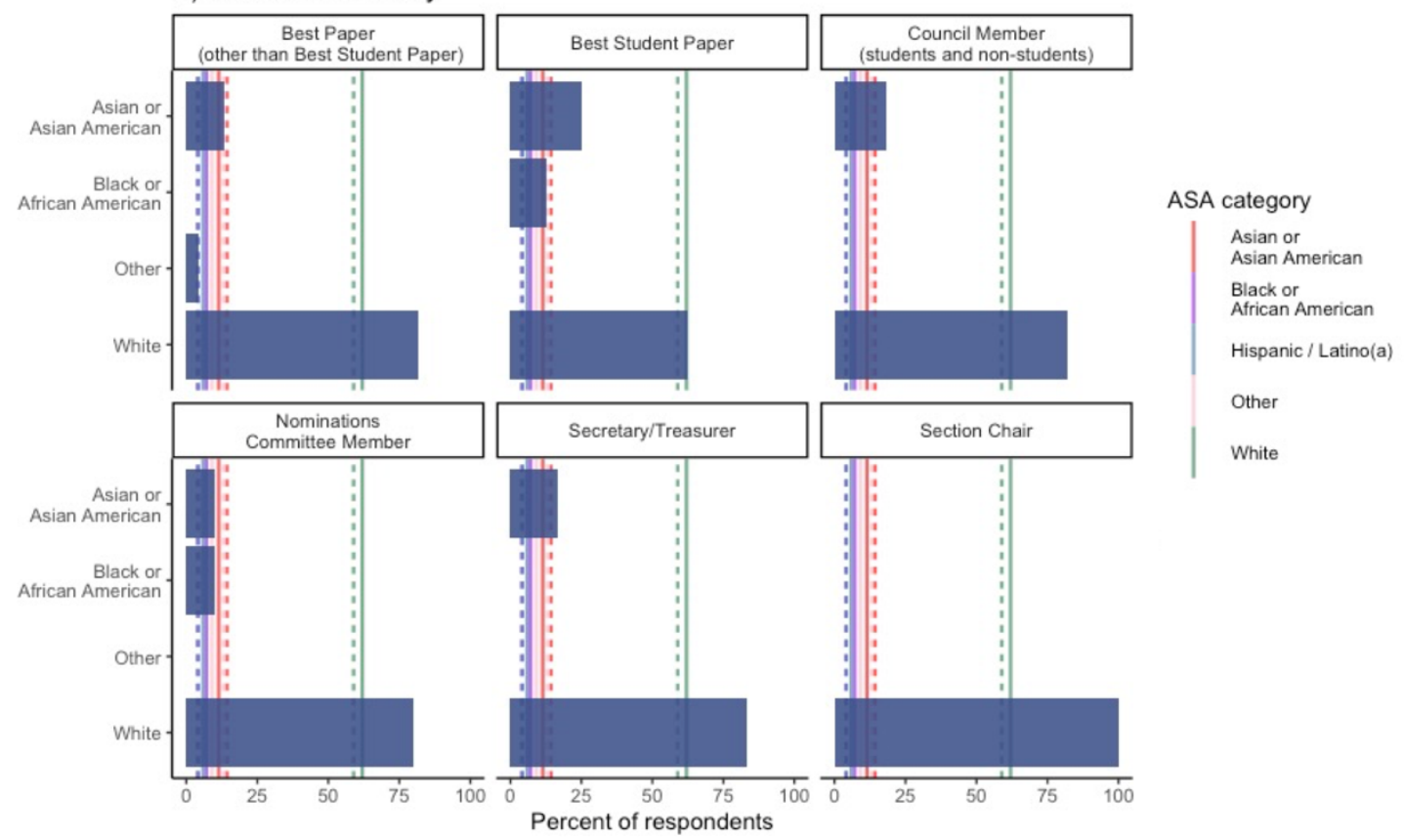

Figure 1. Self-reported gender and racial/ethnic demographics of CITAMS DEI survey respondents across categories of section recognition, with comparisons to ASA- and CITAMS-wide membership. The ASA and CITAMS membership values (solid and dashed lines, respectively) use ASA's chosen demographic labels. Response rates: Best Paper, 58\% $(n=22)$; Best Student Paper, $80 \%(n=8)$; Council Members, 36\% $(n=11)$; Nominations Committee, $53 \%(n=10)$; Secretary/Treasurer, $100 \%(n=6)$; Chair 100\% $(n=6)$. 


\section{References}

Avent-Holt, Dustin and Donald Tomaskovic-Devey. 2019. "Organizations as the Building Blocks of Social Inequalities." Sociology Compass 13(2): e12655.

Dobbin, Frank, Daniel Schrage, and Alexandra Kalev. 2015. "Rage Against the Iron Cage: The Varied effects of Bureaucratic Personnel Reforms on Diversity." American Sociological Review 80(5): 1014-1044.

Mullen, Ann L., and Jayne Baker. 2018. “Gender Gaps in Undergraduate Fields of Study: Do college Characteristics Matter?” Socius 4: 2378023118789566.

Ray, Victor. 2019. “A Theory of Racialized Organizations.” American Sociological Review 84(1): 26-53.

Williams, Christine L., Chandra Muller, and Kristine Kilanski. 2012. "Gendered Organizations in the New Economy." Gender \& Society 26(4): 549-573. 
Supplemental Information

$$
\text { for }
$$

Visualizing Demographic Representation in ASA Sections:

The Case of Race/Ethnicity and Gender in CITAMS

June 30, 2021

\section{Contents}

Appendix A. CITAMS Representation Survey

Appendix B. Code for Producing Visualization 


\section{Appendix A. CITAMS Representation Survey}

The following is the text of the survey sent to participants.

These data will help the CITAMS Diversity, Equity, and Inclusion (DEI) Committee as we assess issues of representation in the section. Because of the small population, these responses are potentially identifiable, but the data will immediately be aggregated, the original survey data will be deleted, and the reported findings will be anonymous. Participation is voluntary. You may leave any question blank. If you have any questions or concerns, please feel free to contact 2020-21 CITAMS Chair Andrew Lindner (alindner@skidmore.edu). Thank you for supporting CITAMS's efforts.

1. In what ways have you served or been recognized by CITAMS? Select all that apply.

Section Chair

Secretary/Treasurer

Council Member

Student Representative

Nominations Committee Member

Award Winner (Other than Best Student Paper)

Best Student Paper Award Winner

2. Which of the following best describes your gender self-identification? Select all that apply.

Female

Male

Genderqueer/Gender Nonconforming

Transgender

Other:

3. Which of the following best describes your racial/ethnic self-identification? Select all that apply.

Check all that apply.

American Indian or Alaska Native

Asian or Asian American

Black or African American

Hispanic or Latinx

White

Native Hawaiian or Pacific Islander

Other:

4. Which of the following best describes your current nationality and location of employment? Mark only one oval. US-born citizen employed in the US

Naturalized US citizen/permanent resident employed in the US

Non-US citizen and non-permanent resident employed in the US

US citizen employed outside the US

Non-US citizen employed outside the US

Other:

5. Do you or have you ever considered yourself a first generation college student? Mark only one oval.

Yes

No 
6. Which of the following best describes your current employment? Mark only one oval.

Non-academic Public sector

Non-academic Private sector

Graduate student

Post-doc

Adjunct faculty member

Non-Tenure Track full-time faculty member

Tenure Track/Tenured faculty member

Emeritus/Retired

Other: 


\section{Appendix B. Code for Producing Visualization}

The following code, written in $\mathbf{R}$, produces the visualization. Any questions should be sent to Daniel Karell (daniel.karell@yale.edu).

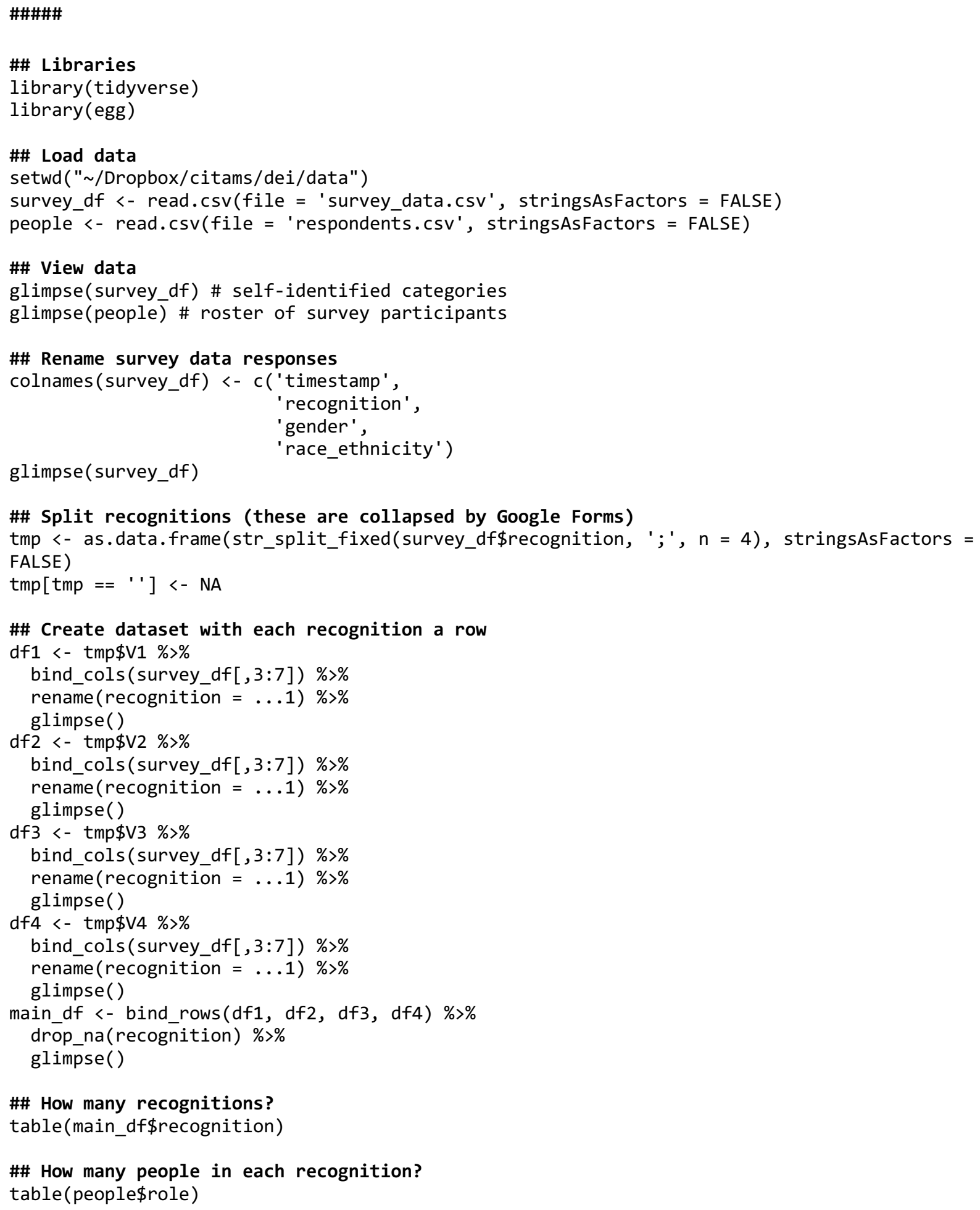




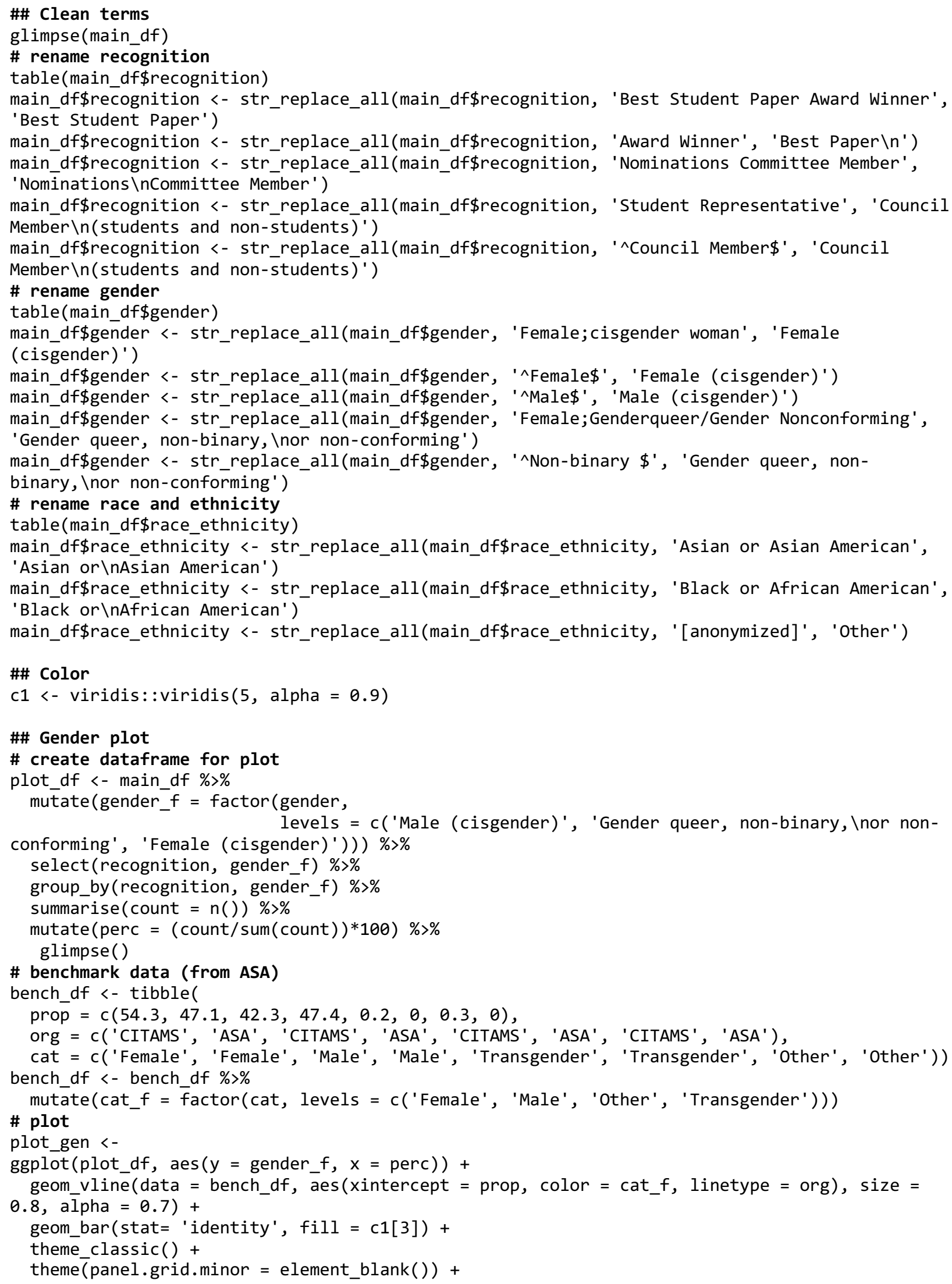




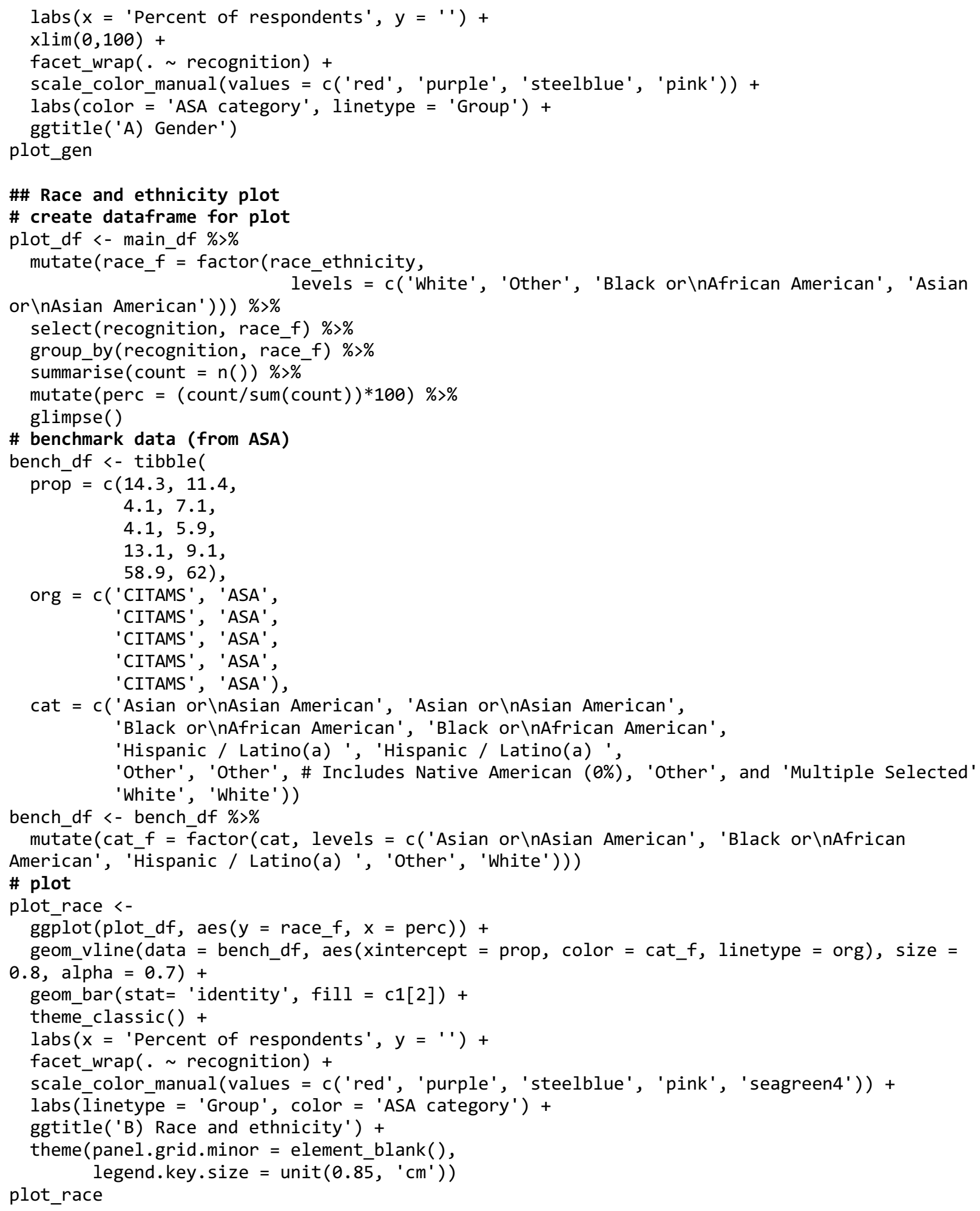

